\title{
Autoestima e saúde mental: Relato de experiência de um projeto de extensão
}

\author{
Self-esteem and mental health: Extension project experience report
}

\author{
Marcia Regina Mendes Nunes ${ }^{[a]}$, Cristiana Montibeller ${ }^{[b]}$, Ketty de Oliveira ${ }^{[c]}$, \\ Rita de Cássia Bosco Arrabaca[c], Sonia Maria Menin Belous Theiss ${ }^{[c]}$
}

\footnotetext{
${ }^{[a]}$ Psicóloga, mestre em Ciência e Cultura pela Universidade do Estado de Santa Catarina (Udesc), professora e coordenadora do Projeto de Extensão do curso de Psicologia da Universidade da Região de Joinville (Univille), Joinville, SC Brasil, e-mail:

marcianunes04@yahoo.com.br

${ }^{[b]}$ Assistente social, mestre em Patrimônio Cultural e Sociedade pela Universidade da Região de Joinville (Univille), professora do curso de Psicologia da Universidade da Região de Joinville (Univille), Joinville, SC Brasil, e-mail: cristiana.montibeller@hotmail. com

${ }^{[c]}$ Acadêmicas estagiárias do Projeto de Extensão do Curso de Psicologia da Universidade da Região de Joinville (Univille), Joinville, SC - Brasil, e-mails: ketheoliveira@ig.com.br, kikassia@yahoo.com.br soniabelous@hotmail.com
}

Recebido: 31/05/2011 Received: 05/31/2011

Aprovado: 21/11/2011 Approved: 11/21/2011

\section{Resumo}

Este trabalho apresenta a experiência desenvolvida em um grupo operativo comunitário através do Projeto de Extensão Homo Sacratu - Grupo de Autoestima e Estudo em Saúde Mental do departamento de Psicologia da Universidade da Região de Joinville (Univille), que se iniciou em 2007 e teve duração de três anos consecutivos. Desde o início teve-se como referência de trabalho a prevenção e promoção da saúde mental com o objetivo de desenvolver um trabalho de apoio e orientação às pessoas adultas que apresentavam algum tipo de sofrimento psíquico, bem como aos familiares dos portadores de transtorno mental; pretendia-se resgatar e melhorar a autoestima dessas pessoas a partir de discussão, reflexão, esclarecimentos e conscientização em grupo, atuando também na comunidade por meio de palestras e atividades de socialização. A autoestima é um dos indicadores mais importantes para o bem-estar psicológico e para uma boa saúde mental. 0 projeto pretendeu enfatizar a importância que o trabalho em grupo pode representar na comunidade, como um recurso amplo priorizando a qualidade de vida em diversos segmentos sociais, principalmente na promoção da saúde mental. Os resultados obtidos mostraram que as atividades desenvolvidas em grupo proporcionaram a cada integrante a autorreflexão, o cuidado de si, e a elevação da autoestima, pois todas as pessoas que participaram do grupo apresentaram melhoras significativas em suas vidas.

Palavras-chave: Extensão. Saúde mental. Grupo operativo comunitário. Autoestima.

\begin{abstract}
The main objective of this work is to present a study made with an operative communitarian group as part of "Homo Sacratu Extension Project - Mental Health Study and Self-esteem group" in the Psychology Department in Universidade da Região de Joinville (Univille). This study started in 2007 for the period of three consecutive years. From the beginning, the basis of this project was to promote mental Health, to prevent any related problems, and to develop a support program for adults who are suffering from any kind of psychological problems. Also to develop an orientation program to offer guidance to the families of those suffering from mental health perturbances. This is done through long group discussions, clarifications and self-awareness, which in turn would lead them to improve their self-esteem. Furthermore, lectures and group socializing achievements were held in the community. Self-esteem is one of the most important indicators
\end{abstract}


of the psychological well being of a person, and good mental health. The aim of the project was to emphasize the importance of a group work and what it can offer to a community group work can be a big source of quality of life in different social segments especially in promoting mental health. Results obtained show that group work activities offered to each participant, self-reflection, self-care and an increase in self-esteem. All participants in the group presented significant improvements in their lives.

Keywords: Extension. Mental health. Operative communitarian group. Self-esteem.

\section{Introdução}

A promoção da saúde é um tema amplamente discutido em diversos campos de pesquisa. Muitas áreas de saúde têm se dedicado ao desenvolvimento de possibilidades de promoção da saúde.

Diante de vários fatos observados em nossa sociedade, é possível verificar que ora entra-se em um processo individualizante, o que pode estar associado ao crescente número de transtornos causados pelo isolamento, ora insere-se na grupalidade, buscando no coletivo novas formas de lidar com situações conflitantes que por vezes causam doenças. O elemento essencial para isso é sem dúvida a solidariedade, onde sentimentos de lealdade e mecanismos de mútua proteção estão presentes. Assim, busca-se de forma incansável esse sentimento nas relações grupais, que parecem hoje uma forma nova e mais tranquila de lidar com situações difíceis de serem resolvidas individualmente.

Este trabalho tem por finalidade descrever a experiência desenvolvida em um grupo operativo comunitário, que teve como objetivo desenvolver um trabalho de orientação e apoio às pessoas em sofrimento psíquico no intuito de resgatar a autoestima para a obtenção de uma melhor qualidade de vida.

\section{Descrevendo a trajetória do grupo}

A ideia de criação desse projeto iniciou-se no ano de 2006, quando a idealizadora, assistente social e professora da Universidade, movida pelas suas inquietações pessoais, se sentiu motivada a encaminhar esse projeto por meio do Departamento de Psicologia à Pró-Reitoria de Extensão e Assuntos Comunitários. 0 projeto foi, então, aprovado no final do mesmo ano e financiado pela universidade; as suas atividades tiveram início em 2007 e perduraram três anos consecutivos.

Desde o início, o projeto contou com a parceria de duas instituições não governamentais - uma que atende a pessoas portadoras de transtornos mentais e familiares e outra religiosa que ofereceu espaço para a execução do projeto na comunidade.

0 fato de o projeto de extensão pertencer ao departamento de Psicologia da Universidade e realizar suas atividades em um espaço cedido por essa instituição religiosa gerou algumas dúvidas por parte de algumas pessoas a respeito de uma possível vinculação entre os objetivos do projeto e o aspecto religioso. No entanto, o espaço foi utilizado somente para desenvolver as atividades do projeto.

A função da Extensão na universidade é propiciar o aprendizado que ultrapasse os espaços eminentemente acadêmicos e possibilite a interlocução entre o conhecimento científico e o conhecimento popular, viabilizando a relação transformadora entre universidade e sociedade. Por esse motivo, a extensão é vista como um canal de comunicação da comunidade, promovendo o fortalecimento e a avaliação do Ensino e da Pesquisa, no que diz respeito à sua relevância social, bem como a avaliação da qualidade do saber produzido.

A possibilidade de acesso ao conhecimento pela sociedade não pode ficar somente sob o domínio da Universidade. Diante disso, o fato de ter a instituição religiosa como parceira nesse projeto não significaria que o sentido da Psicologia como ciência seria comprometida por uma ideia estigmatizada.

Segue um fragmento de um texto escrito por M., 53 anos, participante assíduo do grupo há quase três anos, quando tenta expressar o contentamento de pertencer à equipe:

A Universidade, com este projeto Homo Sacratu, acende uma luz, (num mundo às vezes esquecido), repa- 
rando uma integração social - buscando justiça com uma classe menos privilegiada... a universidade com o Santuário S. C. J. através desta parceria contribui com essa dinâmica maravilhosa, investe no ser humano.... 0 projeto nos traz um novo equilíbrio, integrando e resgatando certos valores esquecidos.

Em 2008, a autora deste estudo foi convidada como psicóloga a coordenar esse projeto, o qual contaria também com uma assistente social e três estagiárias do curso de Psicologia. 0 estágio para os alunos de Psicologia contribuiu para que pudessem aprofundar o tema da saúde mental por meio do estudo teórico e prático, enriquecendo e culminando com o próprio curso em questão.

Nos primeiros contatos, quando se iniciou o grupo, uma característica chamou a atenção da autora do presente trabalho: a ênfase e o interesse apresentados pelo grupo apresentava a respeito de temas relacionados aos transtornos mentais. Termos-chave como "transtorno bipolar", "esquizofrenia", "ansiedade", "depressão" etc. circulavam como guia médico para cada um dos participantes. Muitos já se reconheciam dentro de uma nomenclatura nosográfica, "eu tenho transtorno bipolar", "eu sou uma pessoa depressiva".

O histórico do ano de 2007 demonstra isso pelo grande número de palestras de médicos, psiquiatras, e uma grande necessidade de o grupo se voltar para essas atividades, estudarem temas relacionados aos transtornos mentais, tanto os portadores de transtornos, como os familiares e amigos.

Num primeiro encontro sentiu-se uma grande expectativa em relação à autora deste trabalho, de como poderia contribuir para o grupo como profissional da Psicologia. Percebia-se uma grande demanda do grupo por "respostas" que viessem lhes dar garantia daquilo que já era "suposto saber", um "saber" sobre as doenças. Mas que "saber suposto" era aquele que eles "sabiam"?

Essa busca incessante sobre as doenças ao longo dos encontros foi se transformando em outros questionamentos que giravam em torno da pergunta: "o que eu sei sobre isso em mim?".

Estar em grupo é estabelecer novas redes, é conhecer um pouco da história do outro e, com ele aprender e criar novas formas de ver algo que causa sofrimento. Sobre isso certa vez uma participante com grande inibição relatava emocionada que, quando criança, caminhando para a adolescência, costumava "falar com um poste" e hoje ali ela percebe a importância de ter alguém para poder falar e escutar. Sobre a importância da fala, Kupfer (2000, p. 138) assinala que: “... só a palavra proferida pelo sujeito pode ser por ele ouvida. No entanto, ele precisa dirigir sua fala a alguém para que esta retorne e ele a ouça. Não se ouve se não usar esse recurso".

No recorte das falas durante os encontros é possível verificar a importância do trabalho em grupo na melhoria da qualidade de vida nos mais diversos aspectos: "... eu acho que a gente aprende a conviver melhor, poder falar, ter a oportunidade de falar", P. P., 42 anos; "o contato com os pares facilita o crescimento em grupo...", S. L. S.; "para mim particularmente o grupo é uma segunda família", T.F.S.; "melhorou compreender o mundo, se livrar da angústia, da ansiedade, da competição.... Estar com as pessoas, as conversas, qualquer atividade aqui eu gosto e me ajuda", M. 0.

Esse projeto sempre teve como meta ser referência de trabalho essencialmente de prevenção e promoção à saúde mental, sem caráter terapêutico de diagnóstico e tratamento, mas sim de apoio e orientação às pessoas que possuíam algum tipo de sofrimento psíquico, bem como aos familiares dos portadores de transtorno mental, no intuito de resgatar e melhorar a autoestima dos participantes.

A autoestima é uma das variáveis mais importantes para o bem-estar psicológico e para uma boa saúde mental. 0 conceito de autoestima tem sido estudado e considerado como um importante indicador da saúde mental. Independentemente de sexo, idade, instrução, formação cultural e trabalho, todos precisam ter autoestima, pois esta afeta praticamente todos os aspectos da vida; as pessoas que se sentem bem consigo mesmas, sentem-se bem a respeito da vida, estão aptas a enfrentar e solucionar os desafios com maior responsabilidade e confiança.

O sofrimento psíquico, por sua vez, prejudica o desempenho da pessoa na vida social, familiar, pessoal, no trabalho, nos estudos, na compreensão de si e dos outros, na possibilidade de autocrítica, na tolerância aos problemas e na possibilidade de ter prazer na vida em geral.

Geralmente, a pessoa portadora de um transtorno mental é excluída de diversos grupos e instituições sociais e, por achar-se "diferente", também se exclui. Sendo assim, a família tem uma função primordial de assumir e respeitar o portador, aceitar 
e buscar conhecimento sobre a doença, efetivando, assim, a inclusão social do portador por meio de sua também participação em grupos e, lutar em conjunto com demais familiares e portadores por direitos sociais não garantidos.

Por esse motivo, uma das questões trabalhadas com o grupo foi a conscientização de que a saúde mental não era somente uma questão psicológica, mas uma questão política e social que deveria interessar a todos nós, cidadãos, comprometidos com a vida (Bock, 2002). Dever-se-ia buscar no coletivo novas formas de lidar com situações conflitantes que por vezes nos adoecem, despertando em todos aqueles que participavam do projeto a necessidade do "cuidado de si", através da consciência crítica em relação ao binômio saúde-doença. Essa ação integradora leva em conta a concepção da promoção da saúde, definida na Carta de Ottawa como "o processo de capacitação da comunidade para atuar na melhoria da sua qualidade de vida e saúde, incluindo uma maior participação no controle desse processo", reforçando a responsabilidade e os direitos dos indivíduos e da comunidade pela sua própria saúde.

De acordo com Bock (2002, p. 356-357), "falar em doença implica pensar na cura e também em prevenção..." e, conforme a mesma autora, significa criar estratégias para evitar o seu aparecimento, o que geralmente está relacionado a ações desenvolvidas no meio social.

Com base nessas premissas, enfatiza-se aqui a importância que o trabalho em grupo pode representar na comunidade, como sendo um recurso amplo priorizando a qualidade de vida em diversos segmentos sociais, principalmente na promoção da saúde mental.

Desde o momento do seu nascimento, o indivíduo participa de diferentes grupos numa constante dialética entre a busca de sua identidade individual e a necessidade de uma identidade grupal e social. Assim como o mundo interior e o exterior são a continuidade um do outro, da mesma forma o individual e o social não existem separadamente, pelo contrário, eles se interpenetram, complementam e se confundem entre si.

Nesse sentido, é legítimo afirmar que todo indivíduo é um grupo. Essa afirmativa está evidenciada também em Freud na introdução de seu artigo sobre Psicologia de Grupo e Análise do Ego (1921, p. 91): “... desde o começo a psicologia individual, nesse sentido ampliado, mas inteiramente justificável das palavras, é, ao mesmo tempo, também psicologia social". Logo, mesmo sozinho (ou seja, fora de algum grupo psicológico), no indivíduo há sempre a presença do outro.

Para que o ser humano possa se desenvolver, necessita de um "outro" e é nos grupos que podem ser trabalhadas as relações, possibilitando uma troca de experiências necessárias para a vida. Os grupos proporcionam, entre outras coisas, oportunidades para o enfrentamento dos medos, das angústias, culpas e dos conflitos presentes no cotidiano do homem.

\section{Metodologia}

O projeto teve como procedimentos metodológicos a formação de um grupo operativo comunitário. A classificação como operativo se justifica, no dizer de Zimerman e Osório (1997), pelo fato de que seu funcionamento está centrado em uma determinada tarefa. A tarefa principal do grupo foi no sentido de despertar em todos aqueles que participavam do projeto em questão o "cuidado de si".

0 cuidado de si remete à ideia de "ocupar-se consigo mesmo", dirigir o nosso olhar para a nossa vida. Não podemos ficar esperando que nossos problemas se resolvam. Temos que identificar quais são, descobrir como enfrentá-los, utilizar estratégias e, depois trabalhar. De acordo com Foucault (2004, p. 109), “... ocupar-se consigo, portanto, é ocupação de toda a vida. De fato, se observarmos no período de que lhes falo a maneira como se praticou o cuidado de si, perceberemos que é realmente uma atividade de toda a vida".

Essa ideia do cuidado de si está baseada na atenção que se dá a si mesmo; voltar-se para si é uma escolha que nem todos preferem fazer. É possível constatar essa argumentação na resposta de um participante: "eu busco a cura... eu sei que ela é diária não tem fim... a cura é constante para quem desejar..., C. M.

O conceito de grupo operativo foi criado por Pichón Rivière, psicanalista argentino, na década de 1940. Para esse autor, o que caracteriza os grupos operativos é a relação que seus integrantes mantêm com a tarefa e esta tarefa poderá ser a obtenção de conhecimentos.

Para um grupo tornar-se operativo é necessário ter motivação para a tarefa, mobilidade nos papéis a serem desempenhados e disponibilidade para 
mudanças que se evidenciam necessárias. A esse respeito, Zimerman (1997, p. 76) assinala:

É tão abrangente a conceituação da expressão "grupo operativo" e é tão extensa a gama de suas aplicações práticas que muitos preferem considerá-los como sendo, genericamente, um continente de todos os demais grupos, inclusive os terapêuticos mesmos os especificamente psicanalíticos.... Em linhas gerais, os grupos operativos propriamente ditos cobrem os seguintes campos: ensino-aprendizagem, institucionais, comunitários e terapêuticos.

Grupo operativo consiste em uma técnica de trabalho com grupos, cujo objetivo é promover, de forma econômica, um processo de aprendizagem. Aprender em grupo significa uma leitura crítica da realidade, uma apropriação ativa dessa realidade. Uma atitude investigadora, na qual cada resposta obtida se transforma, imediatamente, numa nova pergunta.

Os grupos operativos trabalham na dialética do ensinar-aprender, o trabalho em grupo proporciona uma interação entre as pessoas, que proporciona que elas tanto aprendam como ensinem, mesmo que seja apenas pelo fato da sua experiência de vida.

Nas intervenções realizadas com os participantes, utilizou-se como metodologia e suporte atividades de socialização, elaboração de relatórios e integração grupal, tais como: técnicas de dinâmica de grupo (apresentação, interação e integração, reflexão e estudo), de recreação (jogos, gincanas, brincadeiras) e danças circulares, bem como subsídios teóricos de trabalhos com grupos operativos.

Além das atividades de socialização em grupo, foram realizadas concomitantemente: várias orientações, encaminhamentos e esclarecimentos de dúvidas e questionamentos a respeito de saúde mental, transtornos psíquicos, meios para melhorar autoestima, onde procurar apoio e tratamento psicoterapêutico ou psiquiátrico.

Várias dinâmicas de grupo foram aplicadas durante $o$ ano nos encontros semanais, todas elas envolviam objetivos específicos de acordo com a necessidade do grupo, seguida de uma avaliação final.

0 planejamento dos encontros e a execução das atividades eram determinados no início de cada ano, conforme necessidades e interesses do grupo: dinâmicas de grupo, palestras, bate-papo profissional, dicas de saúde, momento de afetividade, oficinas, dança circular, canto, círculo de leitura, recreação, discussão e reflexão de temas de interesse de acordo com a necessidade do grupo, atividades artísticas, ginástica, alongamento, passeios, visitas etc. Todas essas atividades eram distribuídas nas quatro semanas do mês, especificamente direcionadas para o terceiro momento, estipuladas dentro do cronograma semanal, apresentado na sequência.

Os encontros ocorriam uma vez por semana, todas as quartas feiras, no período vespertino e com tempo de uma hora de duração; na maioria das vezes, as atividades se estendiam de duas a três horas de acordo com o interesse e necessidade do grupo. A frequência do grupo entre os anos de 2008 e 2009 variou entre 15 e 20 pessoas por encontro.

0 primeiro momento de cada encontro era uma dinâmica de apresentação das pessoas que ali se encontravam. As dinâmicas de apresentação têm como objetivo criar um pequeno entrosamento inicial, fazer com que os participantes saibam os nomes e algumas qualidades e/ou características pessoais de cada integrante. Assim, no início de cada encontro, as estagiárias convidavam os participantes a se apresentarem dizendo seu nome e uma qualidade, uma preferência de comida, lugar, cor, um desejo, ações para elevar a sua autoestima, uma palavra, um sentimento, um objeto, um animal com o qual se identificavam em relação ao grupo ou a vida etc.

A grade curricular do curso de Psicologia contribuiu para que as estagiárias pudessem ter o embasamento teórico e prático para a realização das atividades junto ao grupo. A disciplina de Dinâmica de Grupo e Relações Humanas (DGRH) foi de fundamental importância para atingir o objetivo de elevar a autoestima e o bem-estar psíquico dos participantes.

0 segundo momento era reservado para o "momento de reflexão", no qual qualquer pessoa do grupo podia se manifestar, podendo ser uma mensagem ou frases aleatórias por qualquer pessoa que se manifestasse naquele momento. Alguns participantes traziam pequenos textos que eles mesmos escreviam no seu dia a dia. Esse era um momento muito importante para o grupo, pois permitia muitas vezes "abrir um espaço" para que houvesse a possibilidade da "circulação da palavra", emergindo demandas a serem trabalhadas. Permitir que a palavra circulasse possibilitava às pessoas uma participação ativa e reflexiva pelo que é falado, bem como uma responsabilização por aquilo que é dito.

No terceiro momento, desenvolviam-se atividades programadas, como atividades culturais, oficinas, dança circular, canto, círculo de leitura, recreação, 
discussão e reflexão de temas diversos, atividades artísticas, ginástica, alongamento etc.

No quarto momento, a "terapia do abraço", uma pessoa que estava mais comprometida emocionalmente era convidada a se colocar no centro de uma roda para receber o abraço do grupo. 0 contato físico não é apenas agradável, mas necessário, pois se considerarmos o abraço como uma forma universal de obtermos um contato profundo, físico e afetivo, de certa forma, poderemos usá-lo como um dos possíveis instrumentos terapêuticos. Após esse momento, um lanche era servido para as pessoas, para propiciar uma interação informal.

\section{Discussão}

Em relação ao trabalho desenvolvido, os participantes concordaram com a importância que esse projeto obteve não só para o grupo, mas também para que os mesmos levassem até à comunidade, família e amigos aquilo que aprendiam no decorrer dos encontros. Observa-se isso na resposta de FM:

... o que conheci até agora eu gostei muito. Gosto mesmo. Hoje perdi o ônibus, mas prefiro chegar atrasada a faltar. Fico feliz porque muitas brincadeiras aqui eu já sei da infância. Quando comento a mensagem que eu levo... Quando tem uma mensagem gosto de levar, de passar para os outros. Até para minha irmã no Rio de Janeiro eu já mandei aquela que fala da autoestima, ela fica muito feliz. Obrigada a vocês, vocês são especiais.

Percebeu-se que uma das atividades em grupo que melhoravam a autoestima dos integrantes era as de recreação, pois propiciavam momentos de descontração, alegria, aproximação e ajudavam a integrar o grupo, a fazer rir e a brincar. Os jogos de recreação envolviam principalmente minigincanas com diversas brincadeiras, entre elas: mímicas, corrida, desenho, charadas, organização de festas temáticas como Páscoa, Festa Junina, Natal, contações de histórias etc. A proposta não era apenas brincar no grupo, mas desenvolver atividades que os participantes também pudessem realizar com a família. Isso está evidenciado no depoimento de um participante do grupo quando perguntado se foi alcançado o objetivo da dinâmica: "Objetivo? Em 1o lugar é para ajudar a família, por mim também, mas principalmente a família. Aprender mais com o grupo, aprender coisas boas para poder levar pros filhos, marido, irmãos...", FM.

Segundo Andrade (2005, p. 7), "as dinâmicas de grupo podem proporcionar momentos de crescimento pessoal e coletivo, reconhecimento de si mesmo e dos demais, reciprocidade, respeito às diferenças, tomada de consciência e enfrentamento de problemas em comum".

Outra atividade que foi proposta por uma das estagiárias, com intuito de proporcionar uma vivência em círculo e ao mesmo tempo de interiorização e integração grupal, foi a dança circular, muito aceita pelos integrantes do grupo.

A dança é isto: uma ajuda real, capaz de limpar angústias e temores, de reerguer após a exaustão, a morte, o fracasso. Conseguir transformar a dor na implacável beleza de uma dança é um dos aspectos do mistério da roda. Entramos na roda da Dança Circular e ela, de maneira doce e insistente, nos persegue. Aparece inesperadamente, conforme a necessidade do momento (Lorthiois, 2002, p. 31).

A partir do relato de um dos integrantes do grupo, constatam-se os benefícios promovidos pela dança. Segundo H. H., "o grande benefício é o movimento, você se mexer, se movimentar, o sangue movimenta, a alegria, se sentir amado porque eu acho que uma necessidade grande do ser humano é amar e ser amado".

\section{Resultados: Como estou me sentindo?}

Para mensurar o grau de satisfação dos participantes, foi estabelecido no último período do projeto (quatro meses) um controle de chegada e saída dos mesmos. Como critério adotado para a avaliação, foram utilizadas fichas coloridas (verde, vermelha e amarela), as quais identificavam os níveis de satisfação obtidos pelos participantes. A cor verde correspondia a "muito bem"; vermelha, "muito mal"; e amarela, "razoável".

No Gráfico 1, apresentam-se os percentuais de satisfação manifestada pelos próprios participantes. Pode-se observar que os resultados obtidos refletem a importância de trabalhar a autoestima, constatando-se que, na chegada, os participantes apresentam um grau de satisfação bastante diferente do apresentado no término (saída) dos encontros. 


\section{Chegada}

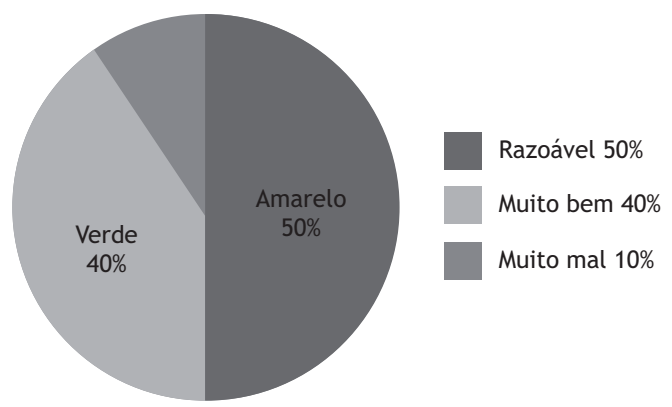

\section{Saida}

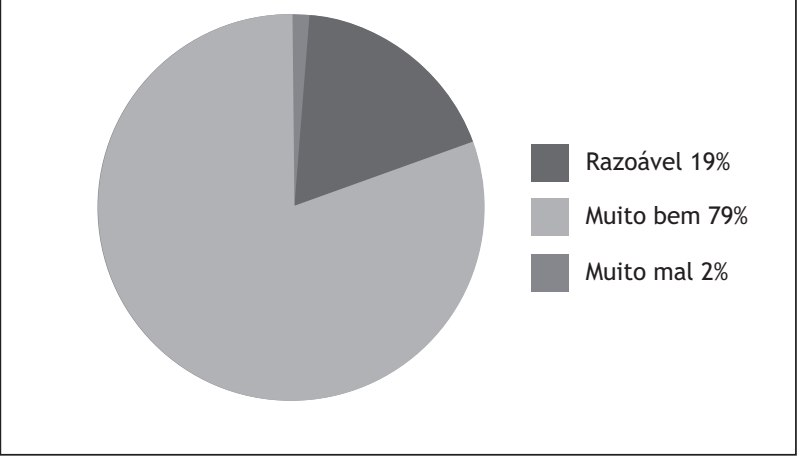

Gráfico 1 - Grau de satisfação dos participantes $(n=130)$ Fonte: Dados da pesquisa.

\section{Considerações finais}

Mediante o trabalho realizado neste projeto, foi possível verificar que as atividades desenvolvidas em grupo contribuíram sensivelmente para a promoção da saúde e melhora da qualidade de vida. Foi possível auferir momentos de satisfação dos participantes nos diversos temas abordados, em palestras, oficinas, dinâmicas, atividades envolvendo dança, canto etc. Foi possível observar que estar inserido em um grupo que trabalha a autoaceitação, a autoestima e a inclusão contribui para uma melhor qualidade de vida; fica evidente que é possível oferecer essa qualidade de vida a todos os indivíduos, independentemente de sua condição, considerada "doente" pela sociedade.

A tarefa do "cuidado de si" se tornou importante para cada participante, pois pensar sobre si nos conduz à compreensão de que temos de nós mesmos como pessoas capazes de fazer escolhas, relacionar-se e conduzir-se adequadamente na relação com o outro.

A Psicologia, atualmente, deve ter o enfoque no compromisso social, possibilitando desconstruir os estigmas e conceitos a priori que a população tem acerca do que vem a ser o sofrimento psíquico.

Esse trabalho proporcionou apresentar a profissão de psicólogo de uma maneira diferente da qual ela é sempre vista, de forma estereotipada, pela sociedade, ou seja, como uma profissão fechada aos problemas do indivíduo do ponto de vista clínico.

A partir dessa experiência, tem-se a esperança de que outras instituições possam abraçar essa causa de "apostar" na prevenção e promoção da saúde mental.

\section{Referências}

Andrade, E. (2005). Construindo relacionamentos através de dinâmicas de grupo. Editora: Qualitymark.

Bock, A. M. B. (2002). Psicologias: Uma introdução ao estudo da psicologia. (13. ed.). São Paulo: Saraiva.

Foucault, M. (2004). A Hermenêutica do sujeito. São Paulo: Martins Fontes.

Freud, S. (1921). Psicologia de grupo e análise do ego. (Vol. XVIII). Rio de Janeiro: Imago. (Edição Standard Brasileira das Obras Psicológicas Completas de Sigmund Freud, 1987).

Kupfer, M. C. M. (2000). Educação para o futuro: Psicanálise e educação. São Paulo: Escuta.

Lorthiois, C. (2002). As danças circulares na roda da vida. In R. C. Lima (Org.). Danças circulares sagradas: Uma proposta de educação e cura. (2. ed.). São Paulo: Triom.

Zimerman, D. E., \& Osorio, L. C. (1997). Como trabalhamos com grupos. Porto Alegre: Artes Médicas. 